\title{
Feasibility of free-breathing diffusion tensor imaging in porcine acute myocardial infarction model
}

\author{
Joon-Won Kang ${ }^{1}$, Seong Hoon Choi ${ }^{2}$, Joon Ho Choi ${ }^{1}$, Yoonyoung Choi ${ }^{1 *}$, So Youn Shin ${ }^{1}$, Jong Chun Park', \\ Tae-Hwan Lim
}

From 17th Annual SCMR Scientific Sessions

New Orleans, LA, USA. 16-19 January 2014

\section{Background}

In vivo DT-MRI is challenging because the motion of the heart and respiration influence the parameters of diffusion tensor imaging, and the most of in vivo DT-MRI is performed under breath-hold. The purpose of this study was to evaluate the feasibility of in vivo DT-MRI without breath-hold with regard to changes in direction-dependent water diffusivity reflecting alterations in tissue integrity such as apparent diffusion coefficients (ADC), fractional anisotropy (FA), and fiber length.

\section{Methods}

Acute myocardial infarction (AMI) was induced by ligation of mid segment of left anterior descending coronary artery (LAD) in sixteen pigs. DT-MRI using a SENSEbased echo-planar imaging technique was acquired using a 1.5-tesla MR scanner with free-breathing state using navigator sequence. With a b-value of $300 \mathrm{~s} / \mathrm{mm} 2$, the diffusion tensor images were obtained for 6 diffusionsensitizing gradient directions at infarcted zone at the mid-ventricular level. Image quality of the acquired DTI was evaluated using a 3-grade system; good, fair, and poor. The ADC, FA, and the fiber length were measured for quantitative analysis. The difference of parameters of DT-MRI was evaluated using Wilcoxon signed rank test. Intraobserver agreement of ADC and FA was evaluated using Bland-Altman plots.

\section{Results}

A total of 7 DTI-MRI's were acquired. Image quality was good in 3 pigs, fair in 2 pigs, and poor in 2 pigs. The

${ }^{1}$ Department of Radiology, Asan Medical Center, Seoul, Korea, Republic of Full list of author information is available at the end of the article acquisition time for DT-MRI was $8 \pm 1.5$ minutes. The infarct zone showed significantly increased ADC than that of the remote zone $\left(8.097 \pm 3.741 \times 10^{-3} \mathrm{~mm}^{2} / \mathrm{sec}\right.$ versus $\left.5.894 \pm 2.985 \times 10^{-3} \mathrm{~mm}^{2} / \mathrm{sec}, \mathrm{P}=0.018\right)$. The FA of the infract zone was seen to be also significantly lower than that of remote zone $(0.393 \pm 0.972$ versus $0.485 \pm 0.145$, $\mathrm{P}=0.018$ ). The fiber length in the infarct zone was seen to be significantly shorter than the remote zone (17.57 \pm $5.46 \mathrm{~mm}$ versus $24.84 \pm 9.79 \mathrm{~mm}, \mathrm{P}=0.018$ ). The difference between the two measurements of ADC and FA didn't show systemic error $(P>0.05)$

\section{Conclusions}

In vivo DT-MRI's of post-infarct myocardium with fair or good image quality can be acquired and the results

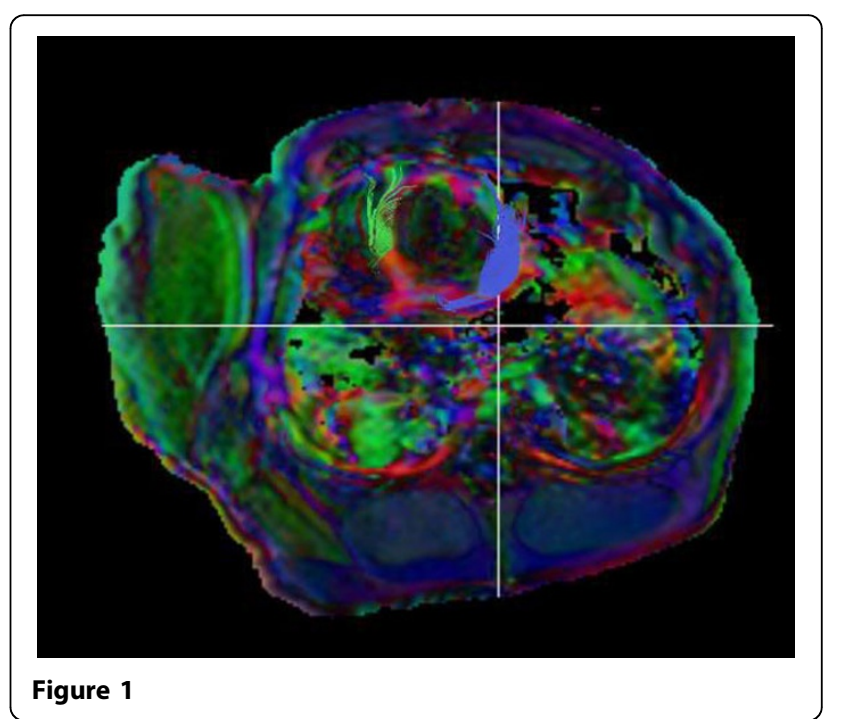


correlated well with those of ex-vivo and breath-hold studies in the literature. This technique may help one understand structural correlates of functional remodeling after infarction especially in the patients who cannot hold one's breath.

\section{Funding}

This work was supported by the National Research Foundation of Korea(NRF) Grant funded by the Korean Government.

\section{Authors' details}

'Department of Radiology, Asan Medical Center, Seoul, Korea, Republic of.

${ }^{2}$ Department of Radiology, Ulsan University Hospital, Ulsan, Korea, Republic of.

Published: 16 January 2014

doi:10.1186/1532-429X-16-S1-P72

Cite this article as: Kang et al:: Feasibility of free-breathing diffusion

tensor imaging in porcine acute myocardial infarction model. Journal of Cardiovascular Magnetic Resonance 2014 16(Suppl 1):P72.

Submit your next manuscript to BioMed Central and take full advantage of:

- Convenient online submission

- Thorough peer review

- No space constraints or color figure charges

- Immediate publication on acceptance

- Inclusion in PubMed, CAS, Scopus and Google Scholar

- Research which is freely available for redistribution

Submit your manuscript at www.biomedcentral.com/submit
C Biomed Central 